\title{
Population cost-effectiveness of the Triple P parenting programme for the treatment of conduct disorder: an economic modelling study
}

\author{
Filipa Sampaio ${ }^{1}(1) \cdot$ Jan J. Barendregt ${ }^{2,3} \cdot$ Inna Feldman ${ }^{1} \cdot$ Yong Yi Lee $^{3,4} \cdot$ Michael G. Sawyer $^{5,6} \cdot$ Mark R. Dadds $^{7}$. \\ James G. Scott ${ }^{4,8,9} \cdot$ Cathrine Mihalopoulos $^{10}$
}

Received: 12 May 2017 / Accepted: 16 December 2017 / Published online: 29 December 2017

(c) The Author(s) 2017. This article is an open access publication

\begin{abstract}
Parenting programmes are the recommended treatments of conduct disorders (CD) in children, but little is known about their longer term cost-effectiveness. This study aimed to evaluate the population cost-effectiveness of one of the most researched evidence-based parenting programmes, the Triple P-Positive Parenting Programme, delivered in a group and individual format, for the treatment of $\mathrm{CD}$ in children. A population-based multiple cohort decision analytic model was developed to estimate the cost per disability-adjusted life year (DALY) averted of Triple P compared with a 'no intervention' scenario, using a health sector perspective. The model targeted a cohort of 5-9-year-old children with CD in Australia currently seeking treatment, and followed them until they reached adulthood (i.e., 18 years). Multivariate probabilistic and univariate sensitivity analyses were conducted to incorporate uncertainty in the model parameters. Triple P was cost-effective compared to no intervention at a threshold of AU $\$ 50,000$ per DALY averted when delivered in a group format [incremental cost-effectiveness ratio (ICER) $=\$ 1013$ per DALY averted; 95\% uncertainty interval (UI) 471-1956] and in an individual format (ICER $=\$ 20,498$ per DALY averted; 95\% UI 11,146-39,470). Evidence-based parenting programmes, such as the Triple $\mathrm{P}$, for the treatment of $\mathrm{CD}$ among children appear to represent good value for money, when delivered in a group or an individual face-to-face format, with the group format being the most cost-effective option. The current model can be used for economic evaluations of other interventions targeting $\mathrm{CD}$ and in other settings.
\end{abstract}

Keywords Population model $\cdot$ Conduct disorder $\cdot$ Children and adolescents $\cdot$ Cost-effectiveness $\cdot$ Parenting programme

\section{Background}

Conduct disorder (CD) is common in children and adolescents, with a global prevalence of $3.6 \%$ of boys and $1.5 \%$ of girls aged 5-19 [1]. CD is characterized by, 'a repetitive and persistent pattern of behaviour in which the basic rights of others or major age-appropriate societal norms or rules are violated' [2,3], and is associated with poor educational outcomes, antisocial and criminal behaviour, substance abuse, poor mental health $[4,5]$, and unemployment $[6,7]$. These outcomes place a high burden on individuals, families, and society [8]. Romeo et al. estimated the mean annual cost of a

Electronic supplementary material The online version of this article (https://doi.org/10.1007/s00787-017-1100-1) contains supplementary material, which is available to authorized users.

Filipa Sampaio

filipa.sampaio@pubcare.uu.se

Extended author information available on the last page of the article child aged 3-8 with severe antisocial behaviour in the United Kingdom (UK) was of $£ 5960$ (in 2002 prices), in terms of health care, educational, and voluntary sector service use, with the greatest cost burden being borne by the family [9]. In a UK longitudinal study of children aged 10 with $C D$, the costs at age 28 were 10 times higher than those of children with no conduct problems in terms of health service use, educational, and justice system costs [10].

Parenting programmes targeted at parents of children with conduct problems are the recommended treatments of CD [11, 12]. These aim to improve parenting styles and parent-child relationships through the reduction of harsh and inconsistent parenting practices and promote the use of positive incentives and enhanced parent-child communication [13]. One of the most widely researched parenting programmes is the Triple $\mathrm{P}$-Positive Parenting Programme [14]. Triple $P$ is a behavioural family intervention, which aims to prevent and/or treat severe behavioural, emotional, and developmental problems in children and adolescents 
by enhancing the knowledge, skills, and confidence of parents. It has five levels of increasing intensity, to address the range of symptom severity of behavioural problems. This intervention comprises a variety of strategies targeting both low- and high-risk families, as well as children with problems in the clinical range, and is one of the most comprehensive and systematized parenting programmes available. There is evidence supporting the effectiveness [15-17] and cost-effectiveness $[12,18]$ of Triple $P$ on child behaviour problems over the short term, but little is known about its long-term cost-effectiveness. Bonin et al., modelled the costs and longer term savings of parenting programmes that could be achieved by reducing the probability of persistent $C D$ among children in the UK, and found them to be cost saving [19]. This model was, however, a scenario analysis and not a full economic evaluation. Furthermore, it did not focus on a specific programme, but rather a range of programmes likely to be implemented in the UK.

The current study conducted an economic evaluation of the Triple P programme, one of the best-researched examples of evidence-based parenting interventions for the treatment of CD in children. Using the Australian population as an example, a health sector perspective was adopted to conduct a cost-utility analysis comparing Triple $\mathrm{P}$ with a 'no intervention' scenario through the use of modelling techniques.

\section{Methods}

\section{Economic evaluation framework}

This study used a standardized economic evaluation modelling framework developed for evaluating health care interventions in the Australian context [20]. The following principles underpinned the evaluation: (1) the adoption of a health sector perspective, with a focus on government as a third-party payer; (2) costs were divided into those accruing to the government and those accruing to individuals and their families; (3) data on intervention effectiveness were sourced from published literature; (4) a cost-utility analysis was performed using disability-adjusted life years (DALYs) averted as the primary outcome; (5) a "partial null" comparator was chosen to represent the theoretical level of disease that would be present if no interventions for this disease were in place [21]; (6) the model used a 2013 reference year to match the latest Global Burden of Disease (GBD) study [22]; (7) costs were measured in 2013 Australian dollars; (8) a 3\% annual discount rate was applied to both costs and health outcomes; and (9) we adopted a threshold value for cost-effectiveness of $\$ 50,000$ per DALY, a commonly accepted value for money threshold in the Australian setting $[20,23]$.

\section{Literature search}

To find evidence on the effectiveness of Triple $\mathrm{P}$, we performed a search of existing reviews alongside a supplementary search of additional studies. The inclusion criteria were: (1) randomized controlled trials or quasi-experimental designs; (2) interventions for the treatment of CD (targeting children with a diagnosis of $C D$ based on structured clinical interviews or cutoffs from disease-specific symptom rating scales); (3) studies reporting diagnostic/clinical outcomes at follow-up; and (4) interventions that are currently used for the treatment of diagnosed CD and would optimally operate within the Australian mental health system (based on advice from a Technical Advisory Panel composed of clinical experts and researchers in the field). This study modelled changes in disorder prevalence that would occur with the Triple P intervention. As such, we excluded studies measuring changes in $\mathrm{CD}$ symptoms (without reporting clinical cutoffs) due to difficulties in determining how changes in a mean and standard deviation score on a symptom scale translate into actual cases of CD. Furthermore, the most recent GBD study has one weight for $\mathrm{CD}$, therefore, making it impossible to meaningfully model changes in severity levels, which failed to achieve clinical remission [1]. A complete description of the search strategy is presented in Section 2 of the Supplementary Appendix.

\section{Intervention effect sizes}

From the literature search, the majority of studies were on the effectiveness of level 4 Triple P. Of these, two studies fulfilled our inclusion criteria [24, 25]. Thus, the group [24] and the individual [25] face-to-face formats were selected for economic evaluation. Martin and Sanders [24] assessed the effectiveness of group Triple P targeting 2-9 year olds, while Sanders et al. [25] assessed the effectiveness of individual Triple $\mathrm{P}$ targeting 3 year olds. Both studies reported outcomes at post-test (follow-up time ranged between 8 weeks after baseline for the group format to 10 weeks after baseline for the individual format). Children were assessed for conduct problems prior to randomization via a telephone consultation. Both studies used the Eyberg Child Behaviour Inventory (ECBI) as the outcome measure instrument [26], and included children who scored within the clinical range of the ECBI intensity scale completed by parents. Group Triple $\mathrm{P}$ included four weekly two-hour group sessions delivered by two psychologists, followed by four weekly individual telephone consultations with an average duration of $30 \mathrm{~min}$. Parents were also given a workbook. Individual Triple $P$ included ten individual sessions, lasting between 60 and $90 \mathrm{~min}$, delivered by one psychologist. 
We calculated an effect size for each intervention at posttest, expressed as a relative risk (RR) with a 95\% confidence interval (CI). This resulted in a relative risk (RR) of: 0.054 (95\% CI 0.003-0.875) for group Triple P and 0.655 (95\% CI 0.484-0.887) for individual Triple P. We assumed that intervention effects at post-test would be maintained up to 1-year follow-up, as the literature supports the impacts of many parenting interventions remain up to 1 year $[12,17$, $27,28]$. A null effect size was assumed thereafter given the lack of published evidence on the sustainability of effects beyond this period. We assumed that study completers would receive a full intervention effect, while dropouts would incur a cost, but receive no benefit. In clinical work with children, $40-60 \%$ drop out of treatment prematurely and hence may not be receiving the benefits of treatment [29]. We defined dropouts as parents who completed less than $20 \%$ of the intervention [29-31] (Table 1).

\section{Study population and intervention pathway}

This study modelled the delivery of group and individual Triple $\mathrm{P}$ targeting children aged 5-9 years with $\mathrm{CD}$ in the 2013 Australian population. We limited the scope of the model to children with CD currently seeking treatment, because the intervention does not include a new case finding component, but rather targets parents of children with $\mathrm{CD}$ who are treatment seeking. This was to reflect current practice, since only $60 \%$ of children with CD in Australia currently access treatment [32]. The selected age group reflects the ages comprised in the trials used to provide the

Table 1 Input parameters and uncertainty ranges used to model health benefits

\begin{tabular}{|c|c|c|c|}
\hline Parameters & Value and uncertainty range & $\begin{array}{l}\text { Distribution } \\
\text { used in PSA }\end{array}$ & Sources \\
\hline \multicolumn{4}{|l|}{ Patient flowchart } \\
\hline $\begin{array}{l}\text { Proportion of parents offered the interven- } \\
\text { tion }\end{array}$ & $60 \%$ (range $40-80$ ) & Pert & Consultation with TAP \\
\hline $\begin{array}{l}\text { Proportion of parents taking up the inter- } \\
\text { vention }\end{array}$ & $60 \%$ (range $40-80$ ) & Pert & NSMHWB [32] \\
\hline $\begin{array}{l}\text { Proportion dropouts (completing } 20 \% \text { of } \\
\text { intervention ( } 2 \text { sessions) }\end{array}$ & $42 \%$ (range $36-49$ ) & Pert & 1 -proportion of completers $[29-31]^{\mathrm{a}}$ \\
\hline $\begin{array}{l}\text { Proportion of parents completing the } \\
\text { intervention }\end{array}$ & $58 \%$ (range $52-65$ ) & Pert & Own meta-analysis of studies [29-31] \\
\hline \multicolumn{4}{|l|}{ Epidemiological inputs } \\
\hline Population & 5-9-year-old children with CD & & 2013 Australian population [38] \\
\hline All-cause mortality & Single age rates & & 2013 Australian life tables [39] \\
\hline Prevalence of conduct disorder & $\begin{array}{l}\text { Average 5-18 age range } 0.026 \text { (see Sup- } \\
\text { plementary Appendix for age- and sex- } \\
\text { specific estimates) }\end{array}$ & Beta & {$[22]$} \\
\hline Remission & $\begin{array}{l}\text { Average 5-18 age range } 0.304 \text { (see Sup- } \\
\text { plementary Appendix for age- and sex- } \\
\text { specific estimates) }\end{array}$ & Gamma & {$[22]$} \\
\hline Incidence & $\begin{array}{l}\text { Average 5-18 age range } 0,009 \text { (see Sup- } \\
\text { plementary Appendix for age- and sex- } \\
\text { specific estimates) }\end{array}$ & Gamma & {$[22]$} \\
\hline Case fatality & $0^{\mathrm{b}}$ & & {$[22]$} \\
\hline Disability weight for conduct disorder & $0.241(95 \% \text { CI } 0.159-0.341)^{\mathrm{c}}$ & Beta & {$[22]$} \\
\hline Effect size group Triple $P$ & $0.054(95 \% \text { CI } 0.003-0.875)^{\mathrm{d}}$ & Lognormal & {$[24]$} \\
\hline Effect size individual Triple $\mathrm{P}$ & $0.655(95 \% \text { CI } 0.484-0.887)^{\mathrm{d}}$ & Lognormal & {$[25]$} \\
\hline
\end{tabular}

PSA probabilistic sensitivity analysis, TAP technical advisory panel, NSMHWB 2014 National Survey of Mental Health and Well-Being-child component, $C I$ confidence interval

${ }^{a}$ See Section 3 of the Supplementary Appendix for detailed methods on the calculation of the proportion of intervention completers and dropouts ${ }^{b}$ As per the 2013 GBD study, case fatality was zero. This is because no estimate of excess mortality due to CD was found in the literature

${ }^{c}$ Unadjusted disability weight used as the cohort of children modelled in this study was symptomatic and determined appropriate for intervention; therefore, the "weighted" disability weight reported in [22] is an underestimate, given it includes children with a less severe condition

${ }^{\mathrm{d}}$ A follow-up study of Sanders et al. [27] reports the outcomes of individual Triple P at 1- and 3-year follow-up (the control group is dropped after post-test) and treatment gains are maintained at both follow-up periods. The initial effect size of the intervention targeting 3 year olds was assumed to remain until 6 years of age 
effectiveness estimates. Although the trial on individual Triple $\mathrm{P}$ targeted children younger than 5 years, our model applied a lower age limit of 5 years, as this reflects the age at which a diagnosis of $\mathrm{CD}$ can be given in clinical practice.

We developed an intervention pathway that was representative of routine health services delivered within the Australian mental health care system. We assumed the following intervention pathway: (1) children with conduct problems attended a first visit with a general practitioner (GP) who performed an initial assessment prior to making a referral to a psychologist; (2) parents were offered either group or individual Triple P; and (3) upon treatment completion, the child was called for at least one follow-up visit with the GP. The following parameters were considered when calculating the eligible population that participated in each intervention: (a) proportion of children with a CD diagnosis; (b) proportion of parents attending an initial GP visit and offered the intervention; (c) proportion of parents taking up the intervention; (d) proportion of parents dropping out; and (e) proportion of parents completing the intervention. We assumed one parent per child. The eligible population was partitioned by sex and 1 -year age groups. All parameters, assumptions, and data sources are shown in Table 1 with the patient flowchart presented in Section 3 of the Supplementary Appendix.

\section{Modelling health benefits}

A population-based multiple cohort decision analytic model with 1-year cycles was implemented in Excel to simulate the disease dynamics with and without the delivery of either group or individual therapy over a 13 -year time horizon. An adapted Dismod-II model, based on a set of differential equations that describe age-specific epidemiological parameters, was used to simulate how a population cohort moves between three health states over time-i.e., healthy, diseased, and dead [33]. The diseased health state included all children with $\mathrm{CD}$, with the prevalence of $\mathrm{CD}$ in the initial cycle (i.e., at year 0) being based on the current prevalence of CD in the 2013 Australian population for each respective age-sex cohort (see Section 4 of the Supplementary Appendix for the corresponding state transition diagram). Transitions between health states corresponded with the epidemiological parameters: incidence, remission, case fatality,

Table 2 Input parameters and uncertainty ranges used in the model for costing analysis

\begin{tabular}{|c|c|c|c|}
\hline Cost parameters (AUS\$) & Value and uncertainty range & $\begin{array}{l}\text { Distribution } \\
\text { used in PSA }\end{array}$ & Sources \\
\hline Cost of general practitioner (first visit) & Government: $\$ 97.27$ & & $\begin{array}{l}\text { MBS items 2700, 2701, } 2715 \text { and } 2717 \\
{[40]}\end{array}$ \\
\hline $\begin{array}{l}\text { Cost of general practitioner (follow-up } \\
\text { visit) }\end{array}$ & Government: $\$ 70.30$ & & MBS item 2712 [40] \\
\hline Cost of MBS-funded psychologist single & Government: $\$ 102.34$; private: $\$ 18.06$ & & MBS items 80,010 and 80,110 [40] \\
\hline Cost of MBS-funded psychologist group & Government: $\$ 25.61$; private: $\$ 4.52$ & & MBS items 80,020 and $80,120[40]$ \\
\hline Cost workbooks Triple P & & & Triple $\mathrm{P}$ practitioner resources ${ }^{\mathrm{a}}$ \\
\hline Every parent & Private: $\$ 35$ & & \\
\hline Every parent group workbook & Private: $\$ 14.95$ & & \\
\hline $\begin{array}{l}\text { Cost uncertainty parameter out-of-pocket } \\
\text { costs }\end{array}$ & Range $\pm 20 \%$ of unit costs & Pert & Protocol \\
\hline \multicolumn{4}{|c|}{ Annual cost of a prevalent case of conduct disorder (for the calculation of cost offsets) } \\
\hline \multirow[t]{2}{*}{ Health care } & $\begin{array}{l}\text { 5-10 years: } \$ 1076.03 \text { (both males and } \\
\text { females) (range } \pm 20 \% \text { ) }\end{array}$ & Pert & $\begin{array}{l}\text { Own calculations (see Section } 5.2 \text { of the } \\
\text { Supplementary Appendix) }\end{array}$ \\
\hline & $\begin{array}{l}\text { 11-18 years: males: } \$ 333.01 \text {; females: } \\
\$ 141.03 \text { (range } \pm 20 \% \text { ) }\end{array}$ & Pert & $\begin{array}{l}\text { Own calculations (see Section } 5.2 \text { of the } \\
\text { Supplementary Appendix) }\end{array}$ \\
\hline \multirow[t]{2}{*}{ Other sector costs ${ }^{\mathrm{b}}$} & $\begin{array}{l}\text { 5-10 years: } \$ 2270.85 \text { (both males and } \\
\text { females) (range } \pm 20 \% \text { ) }\end{array}$ & Pert & $\begin{array}{l}\text { Own calculations (see Section } 5.2 \text { of the } \\
\text { Supplementary Appendix) }\end{array}$ \\
\hline & $\begin{array}{l}\text { 11-18 years: males: } \$ 10,854.29 ; \text { females: } \\
\$ 1027.68 \text { (range } \pm 20 \% \text { ) }\end{array}$ & Pert & $\begin{array}{l}\text { Own calculations (see Section } 5.2 \text { of the } \\
\text { Supplementary Appendix) }\end{array}$ \\
\hline Time cost (per hour) ${ }^{b}$ & $\$ 9.96$ & & (Uprated to 2013 AU\$) [35] \\
\hline Travel cost (per trip) ${ }^{\mathrm{b}}$ & $\$ 24.67$ & & (Uprated to 2013 AU\$) [35] \\
\hline Discount rate & $3 \%$ & & [35] \\
\hline
\end{tabular}

MBS Medicare Benefits Schedule

${ }^{a}$ http://www29.triplep.net/files/pdf/TripleP_Australian_Order_Form_for_PRACTITIONERS.pdf

${ }^{\mathrm{b}}$ Time and travel costs and other sector costs were not included in the base-case analysis, only used in the sensitivity analysis

${ }^{\mathrm{c}}$ A Pert $\pm 20 \%$ distribution was used for every cost parameter which had uncertainty modelled 
and all-cause mortality. The model calculated annual transitions between health states for each single year of age-sex cohorts starting at age 5 until age 9 , until children reached adulthood (i.e., 18 years). CD was modelled along the lines of a chronic, rather than an episodic disorder. Children were assigned a single disability weight for CD (as per the GBD studies $[1,34]$ ) based on the presence or the absence of the disorder. Comorbidities and longer term consequences related to $\mathrm{CD}$ were not modelled, as there is no literature supporting the longer term effectiveness of Triple $\mathrm{P}$ in reducing $\mathrm{CD}$ or related comorbidities.

Aggregated health outcomes were expressed as DALYs, using the disability weight (DW) for $\mathrm{CD}(0.241)$ from the GBD [34] and the prevalence of CD. Only the morbidity component of the DALY was modelled in our study, as there was no evidence of a mortality impact. The model produced incremental cost-effectiveness ratios (ICERs) reported as the net cost per DALY averted. A summary of the epidemiological inputs and their sources are shown in Table 1, and detailed methods described in Section 4 of the Supplementary Appendix.

\section{Costing analysis}

The costs of delivering the intervention included: the cost of psychological assessment by a GP; the cost of a practitioner to deliver group and individual sessions and telephone consultations; and the cost of the workbooks. We assumed that the interventions would be delivered through the publicly-financed community sector. Occasionally, participants were charged out-of-pocket costs, depending on the type of service and the provider. We assumed that the costs for psychological assessment by a GP were fully borne by the government. By contrast, Medicare Benefits Schedule (MBS) items for GP consults and group/individual psychologist visits were split between: the government (who paid $85 \%$ of the listed MBS item fee) and the parents (who paid the remaining $15 \%$ out-of-pocket). We assumed that the cost of programme materials was borne by the parents.

Time and travel costs accruing to parents were excluded from the base-case analysis, but included in a sensitivity analysis. Cost offsets (i.e., treatment costs that are avoided due to the reduction in the prevalence of $\mathrm{CD}$ ), which accrue to the health sector, were included in the base-case analysis. Broader societal perspectives deemed relevant were included in the sensitivity analysis, as large costs associated with CD fall outside the health care sector (e.g., criminal justice).

The model assumed that the interventions were fully implemented and operating under "steady state" conditions-i.e., trained staff and necessary infrastructure were available to deliver the intervention, which operated in accordance with its effectiveness potential [35]. A full description of the methods used in the costing analysis 
are presented in Section 5 of the Supplementary Appendix. All inputs and sources used in the costing analysis are shown in Table 2.

\section{Uncertainty and sensitivity analyses}

ICERs were calculated by dividing the estimated difference in costs by the estimated difference in DALYs averted through the decrease in prevalence of $\mathrm{CD}$ for each intervention compared to "no intervention". We used Ersatz (version 1.31, Sunrise Beach, Australia, available at: http ://www.epigear.com/) to perform a probabilistic uncertainty analysis, using Monte Carlo simulation with 3000 iterations to produce $95 \%$ uncertainty intervals (95\% UIs) around the DALYs averted, net costs, and ICERs. Uncertainty parameters are shown in Tables 1 and 2 .

Univariate sensitivity analyses were performed to investigate the impact of specific input parameters and assumptions on the model outcomes. We modelled the individual impact of: (1) excluding cost offsets related to the health care sector; (2) including cost offsets related to both the health care sector and other non-health sectors;
Fig. 1 Cost-effectiveness plane of the base-case analysis

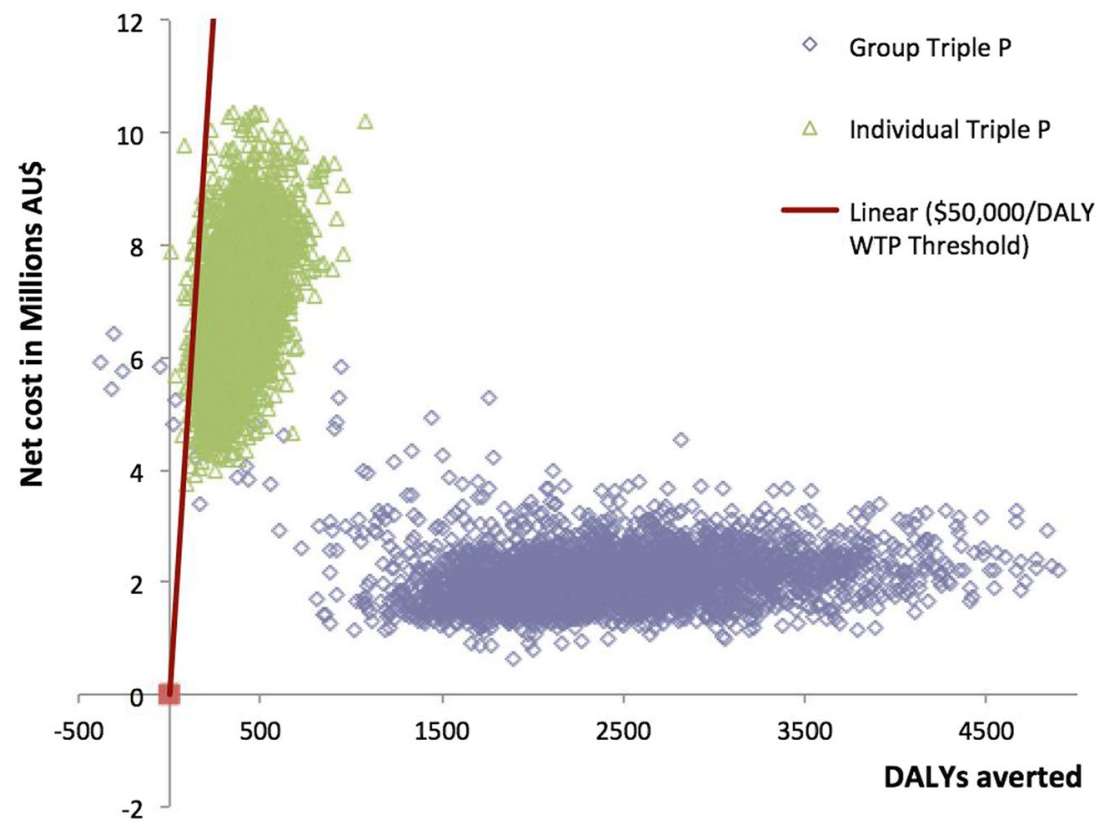

Fig. 2 Cost-effectiveness acceptability curve of the basecase analysis




(3) including time and travel costs; (4a) assuming a 50\% decay rate in effects after year 1 over 5 years (by year 5 the RR is close to the null); (4b) assuming intervention effects persist over 5 years; (5) assuming dropouts get half of the benefit; and (6) applying a 0 and $6 \%$ discount rate to both costs and benefits. We also conducted a threshold analysis to test the impact of varying the effect size of both group and individual Triple $\mathrm{P}$.

\section{Results}

Table 3 shows the base-case cost-effectiveness results. Group Triple $\mathrm{P}$ was very cost-effective relative to a threshold of $\$ 50,000$ per DALY averted, with an ICER of $\$ 1013$. Individual Triple $P$ was cost-effective, with an ICER of \$20,498 per DALY averted. Figure 1 presents the results of the basecase analysis on a cost-effectiveness plane, where estimated cost differences are plotted against estimated differences in DALYs averted between the intervention and "no intervention". In this figure, we can see that the uncertainty iterations for both interventions lie on the north-east quadrant of the plane, where the intervention is more effective and more costly than the comparator. Furthermore, the majority of the iterations fall below the cost-effectiveness threshold of $\$ 50,000$ per DALY averted. The cost-effectiveness acceptability curve (Fig. 2) shows the probability of group and individual being cost-effective for a range of willingnessto-pay (WTP) values a decision maker would be willing to pay per additional DALY averted. It is evidenced that the probability that both intervention formats are cost-effective at a threshold of $\$ 50,000$ per DALY averted is close to one (appx. 99\%), with group Triple $\mathrm{P}$ having a high probability of cost-effectiveness already at very low values of WTP.

The results of the sensitivity analyses are presented in Table 4 . The cost-effectiveness results for both interventions differed little from the base-case when: assuming differential discount rates and assuming dropouts get 50\% of the health benefits. The cost-effectiveness of both interventions improved greatly when assuming intervention effects persisted over 5 years, with group Triple $\mathrm{P}$ becoming cost saving. The exclusion of cost offsets pertaining to the health sector led to slightly higher ICERs for both interventions compared with the base-case. The inclusion of time and travel costs (total time and travel costs: $\$ 2.5 \mathrm{M}$ group; $\$ 2.8 \mathrm{M}$ individual) tripled the ICER for group Triple $\mathrm{P}$, whereas it led to individual Triple $\mathrm{P}$ having a slightly higher ICER and a lower probability of being cost-effective. Group Triple P became cost saving when including cost offsets pertaining to all sectors (cost offsets: $\$ 10.5 \mathrm{M}$ group; $\$ 1 \mathrm{M}$ individual), whereas the ICER for individual Triple $\mathrm{P}$ decreased marginally. Assuming a 50\% annual decay rate of the intervention effect led to group Triple $\mathrm{P}$ becoming cost saving, but with a wide uncertainty interval which intersected the south-east, north-east, and north-west quadrants of the plane-i.e., being either cost saving (dominant) or economically inefficient (dominated). This scenario also resulted in individual Triple $\mathrm{P}$ being more cost-effective, but with a wide uncertainty interval spanning over both the north-west and the north-east quadrants of the plane-i.e.,

Table 4 Results of univariate sensitivity analysis for the base-case model examining the cost-effectiveness of group and individual level 4 Triple $\mathrm{P}$

Sensitivity analysis

Group ICER (95\% UI) (AU\$/DALY averted)

Base-case analysis

(1) No cost offsets (health care)

(2) With cost offsets (health care + other sector costs)

(3) With time and travel costs

(4a) $50 \%$ decay in effect size over 5 years

(4b) Full effect size extrapolated over 5 years

(5) Dropouts get $50 \%$ of health benefit

(6a) Discount rate of $0 \%$

(6b) Discount rate of $6 \%$

$1013(471-1956)$
$2460(1542-3871)$
Dominant $^{\mathrm{c}}$
$3567(2233-5624)$
Dominant $^{\mathrm{c}}(\text { dominant to } 2117)^{\mathrm{a}}$
Dominant $^{\mathrm{c}}$
$927(477-1889)$
$955(439-1779)$
$980(494-2211)$

Individual ICER (95\% UI) (AU\$/DALY averted)

$20,498(11,146-39,470)$
$21,430(11,828-40,682)$
$18,527(9564-37,207)$
$29,903(16,532-56,903)$
13,911 (dominated $^{\text {d }}$ to 77,650$)^{\text {b }}$
$2336(1306-4009)$
$20,248(10,756-38,509)$
$19,820(10,610-38,218)$
$20,894(11,295-41,068)$

\footnotetext{
${ }^{a}$ A proportion of the uncertainty iterations lie in the south-east, north-east, and the north-west quadrants of the cost-effectiveness plane, signifying that there is a likelihood that the intervention is more effective and more costly than the comparator, that it is less costly and more effective than the comparator (dominant), and that it is more costly and less effective than the comparator (dominated)

${ }^{b}$ A proportion of the uncertainty iterations lie in both the north-west and the north-east quadrants of the cost-effectiveness plane, signifying that there is a likelihood that the intervention is less effective and more costly than the comparator (dominated) and that it is more costly and more effective than the comparator

${ }^{\mathrm{c}}$ The intervention is less costly and more effective than the comparator (dominant)

${ }^{\mathrm{d}}$ The intervention is less effective and more costly than the comparator (dominated)
} 
Fig. 3 Threshold analysis to examine the impact of varying the effect size

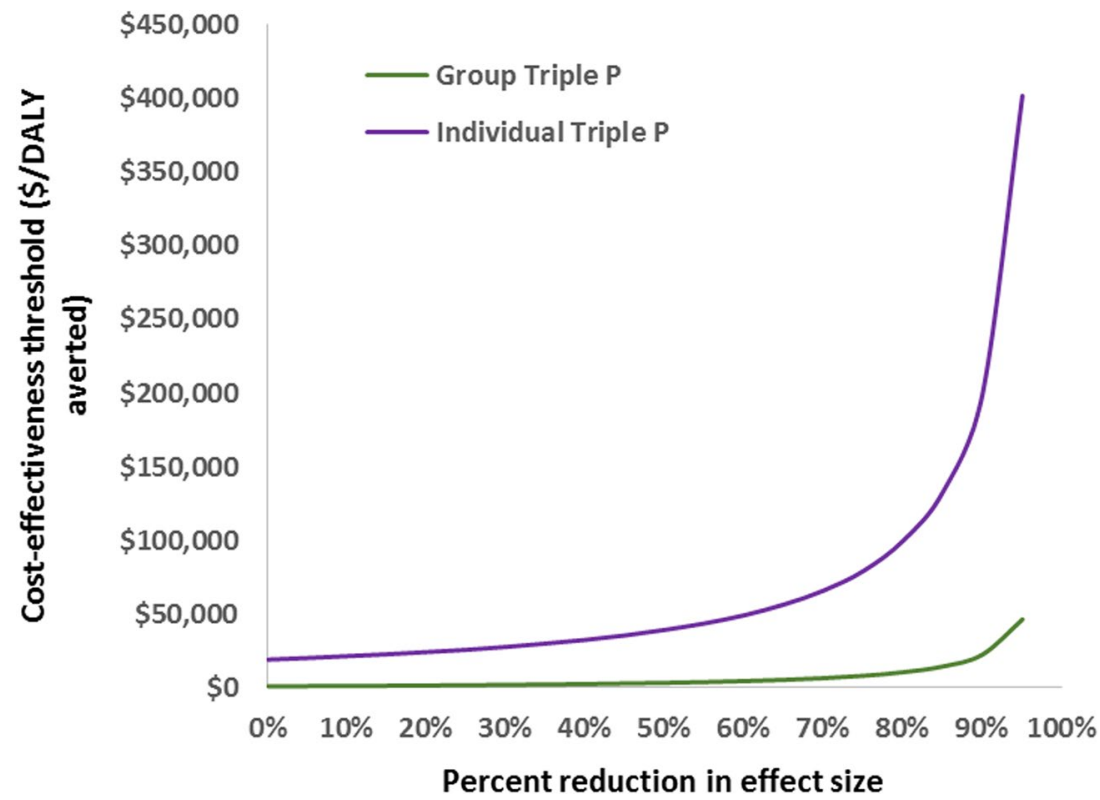

with a double likelihood of being less effective and more costly than the comparator (dominated), and more costly and more effective than the comparator. In the threshold analysis (Fig. 3), group Triple P remained cost-effective to the threshold of $\$ 50,000$ per DALY averted despite variations in effect. Individual Triple P remained below the threshold assuming an effect size $60 \%$ lower than the base-case.

Further details on the sensitivity analyses are presented in Section 6 of the Supplementary Appendix.

\section{Discussion}

\section{Main findings and comparison with other studies}

Using the Australian population as an example, this study used a health care perspective to investigate the cost-effectiveness of a well-known evidence-based parenting intervention, group and individual face-to-face Triple $\mathrm{P}$, compared to no intervention, for the treatment of $\mathrm{CD}$ in children. This study demonstrated that both intervention formats are good value for money, with the group face-to-face format having a higher probability of cost-effectiveness. Univariate sensitivity analyses conducted corroborated the results, demonstrating that the interventions remained cost-effective when making different assumptions about modelling parameters. The biggest impact was that of varying intervention effectiveness estimates. Group Triple P remained cost-effective despite variations in effect, whereas the cost-effectiveness ratio for individual Triple $\mathrm{P}$ went above the threshold of $\$ 50,000$ per DALY when assuming an effect size $60 \%$ lower than the base-case.
This is the first study evaluating the longer term costeffectiveness of parenting programmes in general and of Triple $\mathrm{P}$ in particular for the treatment of $\mathrm{CD}$ using a cost-utility framework. Bonin et al. [19] estimated the costs and longer term savings of parenting programmes in the UK associated with the reduction in the probability of persistent CD among children. They modelled a "generic" parenting intervention, based on various evidence-based programmes that were likely to be implemented in the UK. Their study demonstrated that parenting programmes were likely to reduce the probability of $\mathrm{CD}$ persisting into adulthood, as well as they would entail savings to the public sector in the short run, yielding about US\$27,136 per family over 25 years. These findings cannot, however, be compared to the findings of the current study, as the study from Bonin et al. [19] was not a full economic evaluation, but rather, a cost-offset scenario analysis where inputs were varied according to three intervention scenarios (base, best, and worst cases). Another similar study from Mihalopoulos et al. [18] modelled the expected long-term costs and cost savings of implementing different intensity levels of Triple P (levels $1-5)$ at a population level. The study concluded that Triple $\mathrm{P}$ had the potential to be cost saving over the long-term if at least $7 \%$ of cases of $\mathrm{CD}$ were averted. Although not directly comparable, both studies conducted to date demonstrate the potential of Triple $\mathrm{P}$ being cost saving in the long run.

\section{Implications for policy and practice}

Clinically, while group Triple $\mathrm{P}$ is very cost-effective, it is not always possible or appropriate to provide group-based therapies for all families due to, for instance, limited facilities, trained staff or treatment specifications per se. In this 
instance, it is still cost-effective to provide individual-based Triple $\mathrm{P}$, although in terms of value for health care, groupbased therapy should be the preferred mode of delivery, where possible.

In terms of generalizability of this study's results, a few issues need to be considered. Although the context of the study was Australian, the methods and results have international relevance. Triple $\mathrm{P}$ was developed in Australia, but is implemented in various countries; thus, while referral pathways can differ between countries, the intervention itself would not differ. In our model, we assumed that the interventions, which were the most advanced forms of Triple $\mathrm{P}$, were delivered by psychologists via the publicly-funded Medicare system. This was to reflect the common practice within Australian mental health services, as well as the main professional category likely to deliver this level of Triple P. It is, however, important that readers bear in mind that the cost-effectiveness results may be different in other settings, mostly due to differences between health care systems in terms of structure, financing, price levels, and service provision. Thus, results should be generalized only to countries with similar health care systems to the Australian one, such as the Swedish and the British one, where these interventions would likely be funded publicly. Conversely, the results could dramatically change in contexts such as the United States, where such interventions are likely to be funded privately.

In addition, in this study, only Triple $\mathrm{P}$ was considered (although other parenting programmes have similar effect sizes measured using symptom scales), with the purpose of model testing, due to its well-established implementation in various international settings. Nevertheless, this model is flexible and can be used for economic evaluations of other interventions targeting $\mathrm{CD}$ in the Australian setting, and in other international settings, and thus assist priority setting.

\section{Strengths and limitations}

To the authors' knowledge, this is the first study to assess the cost-effectiveness of Triple $\mathrm{P}$ using a cost-utility populationbased economic modelling approach. Other strengths are the use of the latest data on CD epidemiology; the use of a standardized evaluation framework to avoid methodological confounding, and ensure comparability and transparency of results; and applying conservative assumptions where possible.

There are a few challenges to this kind of research. The estimates were sourced from one study each due to the limited amount of studies fulfilling our inclusion criteria. Given that the therapeutic content of group and individual Triple $\mathrm{P}$ is similar in terms of quantity of therapeutic time but not in terms of content, we would have expected individual therapy to be more effective than group therapy. This large difference in effect size is probably due to the disparity in study population characteristics (i.e., the study on group Triple $\mathrm{P}$ drew participants from academic and general staff in a university setting [24]), whereas the study on individual Triple P targeted low-income areas with high rates of unemployment, where eligible families had at least one adversity factor, such as maternal depression or single parenthood [25]. Families with more adversity factors have been shown to be less likely to respond to treatment [36]. With this in mind, the costeffectiveness of individual Triple $P$ may have been underestimated and that of group Triple P overestimated.

Although the studies used to source the effectiveness estimates only demonstrate the effects of Triple $P$ remain up to 8-10 weeks, our base-case results support the costeffectiveness of Triple $\mathrm{P}$ for the treatment of $\mathrm{CD}$ delivered within the Australian healthcare setting.

Another issue pertains to the use of symptom-based scales to determine clinical caseness and how well they reflect the true impacts of an intervention. Despite the ECBI being a good predictor of $\mathrm{CD}$, using the cutoff as a measure of clinical caseness may underestimate the full potential impacts of the intervention. Impacts on children who had, at start, higher scores, but did not make it through the cutoff would not be captured. We have, however, used all best available evidence, with this limitation in mind.

Importantly, although DALYs are acceptable to Australian decision makers [20], its use as an outcome measure poses limitations. The most substantial problem is the availability of a single disease weight. This makes it impossible to model changes in disease severity without making sweeping assumptions about the distribution of disease and the disability weight by severity [34] (CD does not have differential severity weights; for example, depression has differential weights for mild, moderate, and severe diseases). Consequently, the present study only modelled impacts of the interventions on diagnosed children. The study did not include children with sub-threshold levels of CD or with some levels of problems, who may also benefit from this intervention. Therefore, there is likely to be a substantial underestimation of health gains attributable to reductions in severity. A better approach should specify weights based on disease severity to reflect heterogeneity in health [37].

It is also important to appreciate that the current study only included impacts of the interventions on the children themselves, excluding any benefits that may incur to those directly affected by $\mathrm{CD}$, such as parents, siblings, teachers, and peers. A parenting intervention that successfully improves CD may also reduce caregiver burden and improve the relationship of the child with the parents and with others in the near social circle, which will have impacts on the quality-of-life of these individuals. Impacts on parents are evidenced in the literature demonstrating that parenting interventions have a positive impact on parenting skills and 
parental mental well-being $[11,16]$. It is thus important that economic evaluation includes impacts on all relevant individuals affected by parenting interventions, so that appropriate decisions can be made. Further research may be needed to consider this issue.

\section{Conclusions}

Evidence-based parenting programmes, such as the Triple $\mathrm{P}$, for the treatment of $\mathrm{CD}$ in children, appear to represent good value for money, when delivered in both group and individual face-to-face formats, with the group format being the most cost-effective option. The results should, however, be interpreted with caution, as there are several limitations, including: the insufficient quality of the evidence for the interventions modelled and the restrictive inclusion of diagnosed cases of $\mathrm{CD}$ as the main outcome measure. Furthermore, the current model can be used for economic evaluations of other interventions targeting $\mathrm{CD}$ and in other settings.

Acknowledgements The authors would like to thank Holly Erskine for providing the epidemiological estimates of Conduct Disorder and Raziye Salari for her valuable inputs to the manuscript. This project was funded through the Australian Government National Health and Medical Research Council (NHMRC) Centre of Research Excellence in Mental Health Systems Improvement (CREMSI) (Grant No. APP1041131); and supported by the common grant of major Swedish research funders termed 'Mental health of children and adolescents', FORMAS 259-2012-68. C.M. was supported by an NHMRC Early Career Fellowship (Grant No. APP1035887) and J.G.S. was supported by an NHMRC Practitioner Fellowship (Grant No. APP1105807) during the conduct of this study. The views expressed in this paper are those of the authors and not those of the NHMRC or any other funding body. The funders had no role in study design, data collection and analysis, decision to publish, or manuscript preparation.

\section{Compliance with ethical standards}

Ethical standards The manuscript does not contain clinical studies or patient data. Ethical approval was not required for this work.

Conflict of interest J.J.B. owns Epigear International, which sells the Ersatz software used in the analysis. No other relationships or activities could appear to have influenced the submitted work.

Open Access This article is distributed under the terms of the Creative Commons Attribution 4.0 International License (http://creativecomm ons.org/licenses/by/4.0/), which permits unrestricted use, distribution, and reproduction in any medium, provided you give appropriate credit to the original author(s) and the source, provide a link to the Creative Commons license, and indicate if changes were made.

\section{References}

1. Erskine HE, Ferrari AJ, Nelson P, Polanczyk GV, Flaxman AD, Vos T, Whiteford HA, Scott JG (2013) Epidemiological modelling of attention-deficit/hyperactivity disorder and conduct disorder for the Global Burden of Disease Study 2010. J Child Psychol Psychiatry 54:1263-1274

2. American Psychiatric Association (2013) Diagnostic and statistical manual of mental disorders. American Psychiatric Publishing, Arlington

3. World Health Organization (1992) The ICD-10 classification of mental and behavioural disorders: clinical descriptions and diagnostic guidelines. WHO, Geneva

4. Fergusson DM, Horwood LJ, Ridder EM (2005) Show me the child at seven: the consequences of conduct problems in childhood for psychosocial functioning in adulthood. J Child Psychol Psychiatry 46:837-849

5. Fergusson DM, Horwood LJ, Ridder EM (2005) Show me the child at seven II: childhood intelligence and later outcomes in adolescence and young adulthood. J Child Psychol Psychiatry 46:850-858

6. Knapp M, King D, Healey A, Thomas C (2011) Economic outcomes in adulthood and their associations with antisocial conduct, attention deficit and anxiety problems in childhood. J Ment Health Policy Econ 14:137-147

7. Erskine HE, Norman RE, Ferrari AJ, Chan GC, Copeland WE, Whiteford HA, Scott JG (2016) Long-term outcomes of attentiondeficit/hyperactivity disorder and conduct disorder: a systematic review and meta-analysis. J Am Acad Child Adolesc Psychiatry 55:841-850

8. Erskine HE, Ferrari AJ, Polanczyk GV, Moffitt TE, Murray CJ, Vos T, Whiteford HA, Scott JG (2014) The global burden of conduct disorder and attention-deficit/hyperactivity disorder in 2010. J Child Psychol Psychiatry 55:328-336

9. Romeo R, Knapp M, Scott S (2006) Economic cost of severe antisocial behaviour in children — and who pays it. Br J Psychiatry 188:547-553

10. Scott S, Knapp M, Henderson J, Maughan B (2001) Financial cost of social exclusion: follow up study of antisocial children into adulthood. BMJ 323:191-194

11. Dretzke J, Davenport C, Frew E, Barlow J, Stewart-Brown S, Bayliss S, Taylor RS, Sandercock J, Hyde C (2009) The clinical effectiveness of different parenting programmes for children with conduct problems: a systematic review of randomised controlled trials. Child Adolesc Psychiatry Ment Health 3:7

12. Furlong M, McGilloway S, Bywater T, Hutchings J, Smith SM, Donnelly M (2012) Behavioural and cognitive-behavioural group-based parenting programmes for early-onset conduct problems in children aged 3 to 12 years. Cochrane Database Syst Rev 2:CD008225

13. Webster-Stratton C (1998) Preventing conduct problems in Head Start children: strengthening parenting competencies. J Consult Clin Psychol 66:715-730

14. Sanders MR (1999) Triple P-Positive Parenting Program: towards an empirically validated multilevel parenting and family support strategy for the prevention of behavior and emotional problems in children. Clin Child Fam Psychol Rev 2:71-90

15. de Graaf I, Speetjens P, Smit F, de Wolff M, Tavecchio L (2008) Effectiveness of the Triple P Positive Parenting Program on behavioral problems in children: a meta-analysis. Behav Modif $32: 714-735$ 
16. Nowak C, Heinrichs N (2008) A comprehensive meta-analysis of Triple P-Positive Parenting Program using hierarchical linear modeling: effectiveness and moderating variables. Clin Child Fam Psychol Rev 11:114-144

17. Sanders MR, Kirby JN, Tellegen CL, Day JJ (2014) The Triple P-Positive Parenting Program: a systematic review and metaanalysis of a multi-level system of parenting support. Clin Psychol Rev 34:337-357

18. Mihalopoulos C, Sanders MR, Turner KM, Murphy-Brennan M, Carter R (2007) Does the triple P-Positive Parenting Program provide value for money? Aust N Z J Psychiatry 41:239-246

19. Bonin EM, Stevens M, Beecham J, Byford S, Parsonage M (2011) Costs and longer-term savings of parenting programmes for the prevention of persistent conduct disorder: a modelling study. BMC Public Health 11:803

20. Carter R, Vos T, Moodie M, Haby M, Magnus A, Mihalopoulos C (2008) Priority setting in health: origins, description and application of the Australian Assessing Cost-Effectiveness initiative. Expert Rev Pharmacoecon Outcomes Res 8:593-617

21. Tan-Torres Edejer T, Baltussen R, Adam T, Hutubessy R, Acharya A, Evans DB, Murray CJL (2003) Making choices in health: WHO guide to cost-effectiveness analysis. World Health Organization, Geneva

22. DALYs GBD, Collaborators H, Murray CJ, Barber RM, Foreman KJ, Abbasoglu Ozgoren A, Abd-Allah F, Abera SF, Aboyans V, Abraham JP, Abubakar I, Abu-Raddad LJ, Abu-Rmeileh NM, Achoki T, Ackerman IN, Ademi Z, Adou AK, Adsuar JC, Afshin A, Agardh EE, Alam SS, Alasfoor D, Albittar MI, Alegretti MA, Alemu ZA, Alfonso-Cristancho R, Alhabib S, Ali R, Alla F, Allebeck P, Almazroa MA, Alsharif U, Alvarez E, Alvis-Guzman N, Amare AT, Ameh EA, Amini H, Ammar W, Anderson HR, Anderson BO, Antonio CA, Anwari P, Arnlov J, Arsic Arsenijevic VS, Artaman A, Asghar RJ, Assadi R, Atkins LS, Avila MA, Awuah B, Bachman VF, Badawi A, Bahit MC, Balakrishnan K, Banerjee A, Barker-Collo SL, Barquera S, Barregard L, Barrero LH, Basu A, Basu S, Basulaiman MO, Beardsley J, Bedi N, Beghi E, Bekele T, Bell ML, Benjet C, Bennett DA, Bensenor IM, Benzian H, Bernabe E, BertozziVilla A, Beyene TJ, Bhala N, Bhalla A, Bhutta ZA, Bienhoff K, Bikbov B, Biryukov S, Blore JD, Blosser CD, Blyth FM, Bohensky MA, Bolliger IW, Bora Basara B, Bornstein NM, Bose D, Boufous S, Bourne RR, Boyers LN, Brainin M, Brayne CE, Brazinova A, Breitborde NJ, Brenner H, Briggs AD, Brooks PM, Brown JC, Brugha TS et al (2015) Global, regional, and national disability-adjusted life years (DALYs) for 306 diseases and injuries and healthy life expectancy (HALE) for 188 countries, 1990-2013: quantifying the epidemiological transition. Lancet 386:2145-2191

23. Harris AH, Hill SR, Chin G, Li JJ, Walkom E (2008) The role of value for money in public insurance coverage decisions for drugs in Australia: a retrospective analysis 1994-2004. Med Decis Mak 28:713-722

24. Martin AJ, Sanders MR (2003) Balancing work and family: a controlled evaluation of the Triple P-Positive Parenting Program as a work-site intervention. Child Adolesc Ment Health 8(4):161-169

25. Sanders MR, Markie-Dadds C, Tully LA, Bor W (2000) The triple P-positive parenting program: a comparison of enhanced, standard, and self-directed behavioral family intervention for parents of children with early onset conduct problems. J Consult Clin Psychol 68:624-640

26. Eyberg SM, Pincus D (1999) Eyberg child behavior inventory and Sutter-Eyberg student behavior inventory: professional manual. Psychological Assessment Resources, Odessa

27. Sanders MR, Bor W, Morawska A (2007) Maintenance of treatment gains: a comparison of enhanced, standard, and self-directed Triple P-Positive Parenting Program. J Abnorm Child Psychol 35:983-998

28. Bayer JK, Beatson R, Bretherton L, Hiscock H, Wake M, Gilbertson T, Mihalopoulos C, Prendergast LA, Rapee RM (2017) Translational delivery of Cool Little Kids to prevent child internalising problems: Randomised controlled trial. Aust N Z J Psychiatry 4867417726582. https://doi.org/10.1177/0004867417726582

29. Kazdin AE, Wassell G (1998) Treatment completion and therapeutic change among children referred for outpatient therapy. Prof Psychol Res Pract 29:332-340

30. Kazdin AE (1996) Dropping out of child psychotherapy: issues for research and implications for practice. Clin Child Psychol Psychiatry 1:133-156

31. Kazdin AE, Mazurick JL (1994) Dropping out of child psychotherapy: distinguishing early and late dropouts over the course of treatment. J Consult Clin Psychol 62:1069-1074

32. Lawrence D, Johnson S, Hafekost J, Boterhoven de Haan K, Sawyer M, Ainley J, Zubrick SR (2015) The mental health of children and adolescents. Health Do (ed) Report on the second Australian child and adolescent survey of mental health and wellbeing. Commonwealth of Australia, Canberra

33. Barendregt JJ, Van Oortmarssen GJ, Vos T, Murray CJ (2003) A generic model for the assessment of disease epidemiology: the computational basis of DisMod II. Popul Health Metr 1:4

34. Global Burden of Disease Study C (2015) Global, regional, and national incidence, prevalence, and years lived with disability for 301 acute and chronic diseases and injuries in 188 countries, 1990-2013: a systematic analysis for the Global Burden of Disease Study 2013. Lancet 386:743-800

35. Vos T, Carter R, Barendregt JJ, Mihalopoulos C, Veerman JL, Magnus A, Team A-P (2010) Assessing cost-effectiveness in prevention (ACE-prevention): final report. University of Queensland, Brisbane and Deakin University, Melbourne

36. Reyno SM, McGrath PJ (2006) Predictors of parent training efficacy for child externalizing behavior problems - a meta-analytic review. J Child Psychol Psychiatry 47:99-111

37. Grosse SD, Lollar DJ, Campbell VA, Chamie M (2009) Disability and disability-adjusted life years: not the same. Public Health Rep 124:197-202

38. ABS (2013) Australian demographic statistics. In: Report 3101.0. Australian Bureau of Statistics

39. ABS (2013) Deaths, Australia, 2013. In: Report 3302.0. Australian Bureau of Statistics

40. Australian Government Department of Health and Ageing (2013) Medicare benefits schedule book: operating from 01 July 2013. Commonwealth of Australia: Canberra, Australia 


\section{Affiliations}

\section{Filipa Sampaio ${ }^{1}$ (1) Jan J. Barendregt ${ }^{2,3} \cdot$ Inna Feldman ${ }^{1} \cdot$ Yong Yi Lee $^{3,4} \cdot$ Michael G. Sawyer $^{5,6} \cdot$ Mark R. Dadds $^{7}$. James G. Scott ${ }^{4,8,9} \cdot$ Cathrine Mihalopoulos $^{10}$}

Jan J. Barendregt

j.barendregt@sph.uq.edu.au

Inna Feldman

inna.feldman@pubcare.uu.se

Yong Yi Lee

y.lee5@uq.edu.au

Michael G. Sawyer

michael.sawyer@adelaide.edu.au

Mark R. Dadds

mark.dadds@sydney.edu.au

James G. Scott

james.Scott@health.qld.gov.au

Cathrine Mihalopoulos

cathy.mihalopoulos@deakin.edu.au

1 Department of Public Health and Caring Sciences (IFV), Uppsala University, BMC, Husargatan 3, 75122 Uppsala, Sweden

2 Epigear International, Sunrise Beach, QLD, Australia
3 School of Public Health, The University of Queensland, Herston, QLD, Australia

4 Queensland Centre for Mental Health Research (QCMHR), The Park Centre for Mental Health, Wacol, QLD, Australia

5 School of Medicine, University of Adelaide, Adelaide, SA, Australia

6 Research and Evaluation Unit, Women's and Children's Health Network, Adelaide, SA, Australia

7 Child Behaviour Research Clinic, University of Sydney, Sydney, Australia

8 The University of Queensland Centre for Clinical Research, Herston, QLD, Australia

9 Metro North Mental Health, Royal Brisbane and Women's Hospital, Herston, QLD, Australia

10 School of Health and Social Development, Deakin Health Economics, Deakin University, Melbourne, Australia 